\title{
Comparative Analysis of the Chloroplast Genomes of a novel albino tea "Huabai 1" and the traditional albino tea "Huangjinya" for the revelation of the differences in the gene composition and their evolutionary relationship
}

zhenjun zhao ( $\approx$ zzjswu@126.com )

Research article

Keywords:

Posted Date: February 8th, 2022

DOI: https://doi.org/10.21203/rs.3.rs-1331921/v1

License: (c) (1) This work is licensed under a Creative Commons Attribution 4.0 International License.

Read Full License 


\section{Comparative Analysis of the Chloroplast Genomes of a novel albino tea "Huabai} $1 "$ and the traditional albino tea "Huangjinya" for the revelation of the differences in the gene composition and their evolutionary relationship

Zhenjun Zhao ${ }^{\mathrm{a}^{\dagger} *}$, Qingping Ma ${ }^{\mathrm{b} \dagger}$, Yougen Lou ${ }^{\mathrm{c}}$, Jian Zhang ${ }^{\mathrm{d}}$, Xianchun $\mathrm{Hu}^{\mathrm{a}}$, Junjiang $\mathrm{He}^{\mathrm{a}}$, Xinghui $\mathrm{Li}^{*}$

${ }^{a}$ College of Horticulture and Landscape Architecture, Yangtze University, Jingzhou, Hubei 434025, PR China;

${ }^{\mathrm{b} C o l l e g e ~ o f ~ H o r t i c u l t u r e, ~ N a n j i n g ~ A g r i c u l t u r a l ~ U n i v e r s i t y, ~ N a n j i n g, ~ J i a n g s u ~ 210095, ~ P R ~ C h i n a ; ~}$

${ }^{\mathrm{c}}$ School of Foreign Studies, Yangtze University, Jingzhou, Hubei 434025, PR China;

${ }^{\mathrm{d}}$ College of ChuanCha, YiBin University, Yibin, Sichuan 644000, PR China;

\section{Abstract}

The chloroplast genomes of albino tea variety "Huangjinya" and the newly discovered albino tea resource were analyzed comparatively, and DNA barcodes were used to construct phylogenetic trees between albino tea and other plants in theaceae, aiming to reveal the differences in the albino mechanism between the novel albino tea resource "Huabai 1" and the albino tea variety "Huangjinya" and to clarify the genetic evolutionary relationship between the novel albino tea resource "Huabai 1" and other plants in theaceae from the perspective of chloroplast genome. Studies result have shown that the chloroplast genome size of "Huangjinya" and "Huabai 1" is 158,916 bp, 157,028 bp respectively, LSC (large single-copy)、 SSC (small single-copy) and IR (inverted repeat) are 86,654 bp, 86,590 bp、18,277 bp, 16,463 bp, and 27,900 bp, 26,081 bp respectively for "Huangjinya" and "Huabai 1", with a total of 113 genes annotated were obtained in the chloroplast genome of both albino tea, these include 84 protein coding genes, 24 tRNA genes and 5 rRNA genes. GC content of chloroplast genome of "Huabai 1" was 37.3\%, slightly higher than that of "Huangjinya" (37.22\%). The gene composition, classification and codon preference (preferred to use codons ending in $\mathrm{A} / \mathrm{U}$ ) of chloroplast genome in "Huabai 1" were basically the same as that in "Huangjinya", but the main difference was the length of ycf1 fragment in IR region, the length of "Huabai 1" ycf1 fragment was only $987 \mathrm{bp}$, while that of "Huangjinya" was $2889 \mathrm{bp}$. The construction of phylogenetic tree was based on the four DNA barcodes (matK, $r b c L$, $\operatorname{trnH}-p s b A$, and $y c f 1$ ), and the results showed that $y c f 1$, with the most taxonomic levels, was most suitable for the identification of tea varieties and the interpretation of the evolution of genetic relationships among varieties.

\footnotetext{
*Corresponding author: Zhenjun Zhao, zzjswu@126.com; Xinghui Li, lxhhqw@126.com

$\uparrow$ These authors have contributed equally to this work.
} 
Ycfl cluster showed that the relationship between "Huangjinya" and "Longjing 43" was closer, and that of "Huabai 1" and "Fuding Dabai" was closer. It is speculated that the two tea varieties "Huangjinya" and "Huabai1" may come from different ancestors, and thus led their quite different albino mechanism. This research will provide the basis for the revealing the albino molecular mechanism and phylogenetic development of the novel albino tea resource "Huabai $1 "$.

Keywords: Chloroplast genome; DNA barcode; codon preference; cluster analysis

\section{Introduction}

The tea (Camellia sinensis) resources with abnormal colored new shoots and leaves often have good utilization value in production. Generally, there are several abnormal leaf colors such as purple, yellow and white. The purple shoots of purple bud tea tree usually with high anthocyanin content, the products made with the purple shoots have strong antioxidant effect (Liu et al., 2018). The new shoots of albino tea trees usually have high amino acid content, which has an important effect on improving the fresh taste and other flavor quality of tea (Shu et al., 2020). Therefore, it has attracted wide attention of academia and industry. At present, it has been bred into a series of tea varieties represented by "Baiye 1" and "Huangjinya" (Li et al., 2016; Feng et al., 2014). Recently, these varieties bred on the resource of albino mutant tea tree have become a kind of main varieties developed in tea gardens ( $\mathrm{Li}$ et al., 2016), and have been used on a large scale in production, resulting in good social and economic benefits.

Albino tea plants can be divided into two types: temperature sensitive and light sensitive types according to the albino mechanism. For example, "Baiye 1" belongs to low temperature sensitive albino tea plants (Xiong et al., 2013). "Huangjinya" (a traditional albino tea variety), belonging to photosensitive albino tea plants, is characterized by yellow buds and yellow leaves on tender shoots, under the condition of light, the leaves change the green color to the yellow color and turn green under the condition of shade. In the albino leaves of "Huangjinya", the chlorophyll content is significantly lower than that of shading treatment and ordinary green tea variety "Fuding Dabai", and the contents of violaxanthin, lutein and total carotene increased and the formation of thylakoids and grana in chloroplasts was blocked (Li et al., 2016). In order to further study the molecular mechanism of color change of "Huangjinya", our research group conducted transcriptome analysis on "Huangjinya" under shading treatment and non-shading treatment, and a total of 207 differentially expressed genes were obtained, and these genes were mainly involved in oxidation- 
reduction reactions (especially in the flavonoid and carotenoid pathways related to antioxidant function), suggesting that the leaf color mutation of 'golden bud' may be related to the expression changes of these two pathway genes (Song et al., 2017). In addition, Zhang et al. (2017) find that the increase of amino acid content in the lost green leaves of "Huangjinya" may be related to the acceleration of proteolysis or the slowing down of glycolytic metabolism and the reduction of the synthesis of other nitrogen-containing compounds except amino acids.

The newly discovered albino tea plants have been named as "Huabai 1" with such characters as white buds even at the beginning of germination, higher degree of albino, the white mesophyll and white vein of leaf, and the new young buds and leaves being beautiful jade white, at the same time, their albino period is more than $50 \%$ longer than that of "Huangjinya", according to the detection of the tea quality supervision, inspection and testing center of the Ministry of agriculture of the People's Republic of China, the processed green tea samples made of tender leaves from the newly discovered albino tea plants show excellent quality characteristics: the content of free amino acids for $8.4 \%$, the content of tea polyphenols for $17.7 \%$, the content of caffeine for $2.7 \%$, the content of water extract for $48.6 \%$, and with the high content of free amino acids in the main quality components, the appropriate content of tea polyphenols and caffeine, the high content of water extract, and fresh and refreshing tastes, to be a good prospect for breeding and application of new varieties. Therefore, "Huabai 1" is considered as an excellent germplasm resource of tea plants, but its albinism mechanism and its genetic relationship with other varieties have not been reported.

Chloroplast, an important organelle of green plants, provides necessary energy for plants through photosynthesis. Chloroplasts have their own genomes and are semi-independent organelles encoding 90-100 genes, which play roles in amino acid synthesis, fatty acid synthesis and immune response in plants (Yu et al., 2021; Wang et al., 2021). The main components of the chloroplast genome are protein-coding genes, transfer RNA (tRNA) and ribosomal RNA (rRNA). The chloroplast genome is a circular structure, with a length of $115-170 \mathrm{~kb}$, including two mutually inverted repeat (IR) regions, a large single copy (LSC) region and a small single copy (SSC) region. LSC and SSC are just separated by the two IR sequences (Malte et al. 2018). Chloroplast genome is characterized by haploidy, maternal inheritance, gene number and highly conserved sequence structure, and its sequence variation can provide important information for plant classification and heredity. Therefore, chloroplast genome is often used as an important basis for studying the evolutionary relationship of plants (Wang et al., 2021). For instance, most of the coding genes, 
being single-copy genes except for the double-copy genes in the IR region, in the chloroplast genome are not affected by paralogous genes, so they can provide important analytical evidence for the evolution of higher plants (Saski et al., 2005; Chumley et al., 2006). Wambugu et al. (2015) effectively divided 19 rice varieties with AA genotypes into two groups based on differences of chloroplast genome sequence, one is the South American/African branch (containing two varieties: O. glumaepatula and O. longistaminatapi) and the other is the Australian branch (the largest branch) including 3 Australian varieties and other African and Asian varieties, which helps to further understand the evolutionary relationship between cultivated rice and wild rice, and also provides a reference basis for the utilization of wild rice in rice genetically improved varieties.

In this study, the chloroplast genome sequences of traditional albino tea "Huangjinya" and newly discovered albino tea "Huabai 1" were obtained by high-throughput sequencing. The composition and variation of chloroplast genome of albino varieties "Huangjinya" and "Huabai 1"were compared and analyzed by analyzing their sequence structure through the methods such as drawing the genome book genome map and analyzing its sequence structure, and the phylogenetic tree was constructed by using the intergenic sequences of the four common DNA bar code genes $m a t K, r b c L$, $y c f 1$ and $t r n H-p s b A$ in the chloroplast genome and the sequences of other tea varieties and plants in camellia to analyze the genetic relationship between varieties in order to provide a theoretical basis for revealing the albinism mechanism of "Huabai 1" and its evolutionary relationship with other varieties.

\section{Materials and methods}

\subsection{Plant materials}

The two-year-old clonal cuttings "Huangjinya" and "Huabai 1" cultivated in the experimental field of Nanjing Agricultural University were selected as the test materials. The new shoots with one bud and two leaves were taken (the leaves phenotype of "Huangjinya" and "Huabai 1" showed in Fig.1), frozen with liquid nitrogen and stored at $-80^{\circ} \mathrm{C}$ for DNA extraction.

\subsection{DNA extraction and machine sequencing}

DNA was extracted by using DN15-Plant Genomic DNA Rapid Extraction Kits (Adlai, Beijing) according to the instructions. The $1.2 \%$ agarose gel electrophoresis, Agilent 2100 biological analyzer (Agilent, USA) and NanoDrop ND-1000 spectrophotometer (NanoDrop, USA) were used to detect DNA quality and concentration. The range of OD260/280 between 1.7-1.9 indicated that the DNA quality was good. 
124 After qualification of detecting the sample genome DNA, the DNA was segmented, then with a series of reactions including purification of the fragmented DNA fragments, the end repair, adding 3' A tail and joining ligation adapters and so on, and selection of the fragment size by $1.2 \%$ agarose gel electrophoresis, PCR amplification used to form a sequencing library. After the library preparation being qualified, the Illumina HiSeq 2500 platform was used to sequence.

\subsection{Processing and analysis of sequencing data}

Raw Data were filtered to remove joint sequences and low-quality Reads to obtain high-quality Clean Data. Clean Data were assembled using NOVOPlasty software according to the chloroplast genome sequence of the known variety "Longjing 43" (Genbank Accession Number: KF562708) to obtain the results of chloroplast sequence assembly. The chloroplast genome was annotated by CpGAVAS software and online website tool: GeSeq. CDS sequences were obtained by BLAST comparison of reference genomes or databases through the online website tool GeSeq, prediction of tRNA based on tRNAscan, prediction of single-copy regions and reverse repeat sequences using CpGAVAS software based on Vmatch, and, at last, chloroplast genome maps made by GeSeq based on OGDRAW (Wang et al.,2020). The genome sequence was analyzed by SSR (through software and GRAMENE MISA online website (http://archive.gramene.org/db/markers/ssrtool)), and the number of SSR repeats set to 5 .

\subsection{Phylogenetic tree analysis}

DNA barcode, a new technology for identifying species information proposed in recent years, can identify species quickly and accurately (Somaratne et al., 2019). Because the chloroplast genome, relatively conservative, has certain variation, many genes or intergenic region sequences can be used as DNA barcodes to identify species and explore genetic relationships, such as matK and $r b c L$. In this study, based on the known chloroplast genome information of tea plant landed by NCBI, the sequences of four common DNA barcodes $m a t K 、 r b c L 、 y c f l$ and trnH-psbA of chloroplast genome screened, CLUSTW used for sequence alignment, MEGA X was used to construct the phylogenetic tree. Neighbour-joining method as the statistical method, Maximum Composite Likelihood as the analysis model, Camellia oleifera was the root of the phylogenetic tree in this study.

\section{Results}

\subsection{Chloroplast genome composition of "Huangjinya"}

After sequencing and assembly, the chloroplast genome size of "Huangjinya" was 158,916 bp, of which the sizes of LSC, SSC and IR were $86,654 \mathrm{bp}, 16,463 \mathrm{bp}$ and $27,900 \mathrm{bp}$, respectively. A total 
155 of 113 genes were obtained by annotation, including 84 protein-coding genes, 24 tRNAs and 5 rNAs.

156 The GC content of chloroplast genome in "Huangjinya" was $37.22 \%$. The information distribution 157 of gene, exon and intron in chloroplast genome of "Huangjinya" shown in Table 1, CLPP and ycf3 158 genes contained two introns, and other genes contained only one intron. As shown in Table 2,3, 159 there were 29 high-frequency codons (relative synonymous codon usage RSCU $>1$ ) in the 160 "Huangjinya" chloroplast genome with more preference to use codons ending in a / $\mathrm{u}$, which 161 indicated that the chloroplast genome in "Huangjinya" had an obvious preference for synonymous 162 codon selection. The annotation results of chloroplast genome in "Huangjinya" showed that the 163 genes constituting the chloroplast genome were mainly concentrated in photosystem I, photosystem 164 II, cytochrome b / f complex, ATP synthase, RNA polymerase, etc. (Fig.2).

\subsection{Chloroplast genome composition of "Huabai 1"}

166 The chloroplast genome size of "Huabai 1", obtained by sequencing, was $157028 \mathrm{BP}$, and the 167 length of LSC, SSC and IR were 86590 BP, 18277 BP and 26081 BP respectively. One hundred and 168 thirteen genes were contained in the chloroplast genome of "Huabai 1", including 84 protein coding 169 genes, 24 tRNAs and 5 rRNAs, which was consistent with the number and composition of the 170 chloroplast genome in "Huangjinya". The GC content of chloroplast genome in "Huabai 1" was $17137.3 \%$, which was slightly higher than that in "Huangjinya". As shown in Table 1, the gene 172 distribution and the composition of exon and intron in "Huabai 1" were consistent with that of 173 chloroplast genome in "Huanginya", and the other genes only had one intron except genes clpP and 174 YCF3 with containing two introns distributed on LSC. Codon preference analysis showed that there 175 were 29 high-frequency codons in the chloroplast genome of "Huabai 1", and the RSCU value was 176 very close to that in "Huangjinya", which indicated that the codon use preference between the two

177 varieties was relatively close, the chloroplast genome was relatively conservative and the difference 178 was small (Table 2,4). The gene composition and classification of chloroplast genome in "Huabai 179 1" were basically the same as that in "Huangjinya", but the main difference was the length of ycfl

180 fragment in IR region, the length of "Huabai 1" ycf1 fragment was only $987 \mathrm{bp}$, while that of 181 "Huangjinya" was 2889 bp (Fig. 3).

1823.3 Analysis of chloroplast genomes of "Huangjinya" and "Huabai 1" via Simple Sequence Repeat $183 \quad(S S R)$

184 In this study, 63 SSRs were found in the chloroplast genome of "Huangjinya", including 59 single 185 base repeat SSRs (monomers) and 4 double base repeat SSRs (dimers). The SSR types of chloroplast 

genome in "Huangjinya" was dominated by A/T (Table 5). Fifty-six SSRs were identified in the chloroplast genome of 'Huabail', including 52 single base repeat SSRs and 4 double base repeat SSRs. The SSR types of chloroplast genome in "Huabai 1" were also dominated by A/T, and the SSR location was highly consistent with that of "Huangjinya", indicating that the chloroplast genomes of the two tea varieties were highly conserved.

\subsection{Analysis of genetic relationship among different varieties via chloroplast genome DNA bar code}

As shown in Figure 4, Camellia oleifera was a single branch in the construction of the phylogenetic tree based on the four DNA bar code sequences, indicating that the four DNA bar codes can distinguish plants at the species level. However, for the identification of tea varieties or cultivated varieties, 10 tea varieties can only be divided into two groups by $r b c$, tea trees divided into three groups by the $m a t K$ and $t r n H-p s b A$ intergenic region, and the composition of each species is completely the same. Tea varieties were divided into multiple groups according to $Y c f l$ with the most grouping levels and being more specific. Among the four DNA bar code sequences, $y c f l$ had the best classification effect. "Longjing 43" and "Huangjinya" clustered into one category was consistent with the classification results of matK and trnH-psbA, indicating that the genetic relationship between "Huangjinya" and "Longjing 43" was close; according to the phylogenetic tree of $y c f 1$ clustering, "Huabai 1" and "Fuding Dabai " were clustered into one category, while in the other three DNA bar code phylogenetic trees, these two varieties can't be separated from other varieties. Therefore, $y c f l$ is most suitable for tea variety identification and explaining the evolution of genetic relationship among varieties.

\section{Discussion}

Chloroplast genome can provide important reference value for plant taxonomy and phylogenetic reconstruction. In this study, the whole chloroplast genomes of two albino tea varieties "Huangjinya" and "Huabai 1" were obtained by the method of the second-generation sequencing. The results showed that the chloroplast genome structures of the two albino tea varieties "Huangjinya" and "Huabai 1" were very similar, both contained LSC, SSC and two IR regions. The main difference between the chloroplast genome structures of the two albino tea varieties is in the length of IR region. The IR region length of the albino tea "Huangjinya" is longer by $1819 \mathrm{bp}$ than that of the albino tea "Huabai 1", indicating that the IR region of chloroplast genome plays a less and less role in the evolution of the tea plants and gradually will be cut out.

Generally speaking, the genetic code of an organism consists of 61 codons, and each amino acid 
is encoded by 2-6 synonymous codons, excluding Met and Trp. And codon preference widely existed in prokaryotic and eukaryotic systems, therefore it is of great significance to understand intraspecific or interspecific gene codon preference for studying species evolution (Ma et al., 2015; Ma et al., 2016). Mutation and natural selection as the main factors in the evolution of species affect codon preference in gene translation. Codons with high translation efficiency are generally chosen by highly expressed genes, so natural selection is the main factor affecting the use preference of codon of highly expressed genes. However, codon preference is mainly determined by mutation in the genes with low expression (Wang et al., 2014). Codons ending in $\mathrm{A} / \mathrm{U}$ are as the main codon preference in the chloroplast genome of tea tree and, both the number of codons and the codon usage parameters (RSCU value and CAI value) in the chloroplast genome of "Huangjinya" and "Huabai $1 "$ are very close, indicating that the chloroplast genome of tea tree is relatively conservative.

DNA bar code is a species identification technology emerged in recent years, and a section of DNA region is used to identify species quickly, accurately and automatically (Bi et al., 2018; Feng et al., 2018). Due to chloroplast genome sequences with the advantages such as the simple and stable genetic structure, monogeneic inheritance and unified amplification and obtainment of target sequences, chloroplast genome sequences are often used to study plant molecular phylogeny. At present, the commonly used chloroplast DNA barcode sequences include gene coding regions of $r b c L$ and $m a t K$ and so on (Parveen et al., 2017). However, conserved coding regions with little variation contained in these gene sequences were often unable to distinguish closely related species, especially those species with more close relationship in evolution. In order to improve the resolution of plant phylogenetic analysis, some non-coding region or intergenic region sequences have been applied to phylogenetic reconstruction. In this study, tea trees can only be divided into two categories by the chloroplast coding gene $r b c L$ as a DNA bar code to construct a phylogenetic tree: one is tea tree with the small and medium leaves represented by "Fuding Dabai" and "Longjing 43", and the other is tea tree with the large leaves represented by "Assam". Eleven tea varieties are divided into three categories by intergenic region sequence of another two encoding genes matK and $\operatorname{trnH}-p s b A$, "Huangjinya" and "Longjing 43" are clustered separately into a single group, indicating that the clustering effect of $m a t K$ and $t r n H-p s b A$ intergenic region sequence on tea varieties is better than that of $r b c L$. Eleven tea varieties can be divided into multiple different populations by gene $Y c f 1$, among them, albino tea "Huangjinya" and normal tea "Longjing 43" with the closest genetic relationship, and normal tea "Fuding Dabai" and albino tea "Huabai 1" with the 
closest genetic relationship, and albino tea "Huangjinya" and "Huabai 1"are clustered into two different groups due to the relatively distant genetic relationships. The other two "Assam" species are clustered into one group, indicating that ycf1 is the most suitable for DNA bar code to identify tea varieties.

\section{Conclusion}

The chloroplast genome sequences of two albino tea varieties "Huangjinya" and "Huabai 1" were obtained by high-throughput sequencing. The chloroplast genes of the two albino tea varieties are conservative, and the main difference lies in the length of IR region. Both tea varieties, preferred by using codons ending in $\mathrm{a} / \mathrm{u}$, have the strong codon preference. Cluster analysis shows that $y c f 1$ sequence located in IR region is the most suitable DNA bar code to identify different tea varieties.

\section{Declaration of Competing Interest}

The authors declare that they have no known competing financial interests or personal relationships that could have appeared to influence the work reported in this paper.

\section{Funding sources}

This study was supported by National Natural Science Foundation of China (31870682, 31972464), the China Agriculture Research System of MOF and MARA, Jiangsu agricultural science and technology innovation fund [CX (20)3006].

\section{Acknowledgments}

We thank Dr. Yuehua Ma (Central laboratory of College of Horticulture, Nanjing Agricultural University) for assistance in using PCR (T100, Bio-rad).

\section{References}

Bi Y., Zhang M., Xue J., Dong R., Du Y. and Zhang X. 2018. Chloroplast genomic resources for phylogeny and DNA barcoding: a case study on Fritillaria. DNA Barcode Chloroplast 8:1184.

Chumley T.W., Palmer J.D., Mower J.P., Fourcade H.M., Calie P.J., Boore J.L. and Jansen R.K. 2006. The complete chloroplast genome sequence of Pelargonium $\mathrm{x}$ hortorum: organization and evolution of the largest and most highly rearranged chloroplast genome of land plants. Molecular Biology and Evolution 23:2175-2190.

Feng L., Gao M.J., Hou R.Y., Hu X.Y., Zhang L., Wan X.C. and Wei S. 2014. Determination of quality constituents in the young leaves of albino tea cultivars. Food Chemistry 155: 98104. 
Feng S., Jiao K., Zhu Y., Wang H., Jiang M. and Wang H., 2018. Corrigendum: Molecular identification of species of Physalis (Solanaceae) using a candidate DNA barcode: the chloroplast psbA-trnH intergenic region. Genome 61:1.

Li C.F., Xu Y.X., Ma J.Q., Jin J.Q., Huang D.J., Yao M.Z., Ma C.L. and Chen L. 2016. Biochemical and transcriptomic analyses reveal different metabolite biosynthesis profiles among three color and developmental stages in 'Anji Baicha' (Camellia sinensis). BMC Plant Biology 16: 195.

Liu L. F., Zhou Y., Lin L., Xiao W. J. and Gong Z. H. 2018. Establishment of hplc method for anthocyanins determination of purple bud tea tree. Food \& Machinery 34(2):67-72.

Li M., Zhang L.J., Shi M., Lin X.M., Zheng X.Q., Wang K.R., Lu J.L. and Liang Y.R. 2016, Effect of light-shading on chemical composition of spring shoots on light-sensitive Albino tea plants, Journal of Tea 42(3): 150-154.

Li N., Yang Y., Ye J., Lu J., Zheng X. and Liang Y. 2016. Effects of sunlight on gene expression and chemical composition of light-sensitive albino tea plant. Plant Growth Regulation 78: 253-262.

Ma, Q., Li, C., Wang, J., Wang, Y. and Ding, Z. 2015. Analysis of synonymous codon usage in FAD7 genes from different plant species. Genetics and Molecular Research 14:1414-1422.

Ma Q.P., Hao S., Chen X. and Li X.H. 2016. Validation of reliability for reference genes under various abiotic stresses in tea plant. Russian Journal of Plant Physiology 63:423-432.

Malte M., Birte P., Céline B.J., Maike P.D., Zoéwindé B., Bernd D., Ian S. and Birgit K. 2018. Complete Chloroplast Genome Sequences of Four Meliaceae Species and Comparative Analyses. International Journal of Molecular Sciences 19(3):701.

Parveen I., Singh H.K., Malik S., Raghuvanshi S. and Babbar, S.B. 2017. Evaluating five different Loci (rbcL, rpoB, rpoC1, matK and ITS) for DNA Barcoding of Indian Orchids. Journal of Inequalities Applications 2014:1-10.

Saski C., Lee S.B., Daniell H., Wood T.C., Tomkins J., Kim H.G. and Jansen R.K. 2005. Complete chloroplast genome sequence of Gycine max and comparative analyses with other legume genomes. Plant Molecular Biology 59:309-322.

Shu Z.F., Wang L.L., Lou Y.H., Ji Q.Y., Shao J.N., Liu Y. and He W.Z. 2020. Research progress on accumulation mechanism of L-theanine in albino tea plant. Food research and development 41(17):217-224. 
Somaratne Y., Guan D. L., Wang W. Q., Zhao L. and Xu S. Q. 2019. Complete chloroplast genome sequence of xanthium sibiricum provides useful DNA barcodes for future species identification and phylogeny. Plant Systematics and Evolution 305:949-960.

Song L., Ma Q., Zou Z., Sun K., Yao Y., Tao J., Kaleri N.A. and Li X. 2017. Molecular link between leaf coloration and gene expression of flavonoid and carotenoid biosynthesis in Camellia sinensis cultivar 'Huangjinya'. Frontiers in Plant Science 8: 803.

Wambugu P.W., Brozynska M., Furtado A., Waters D.L. and Henry R.J. 2015. Relationships of wild and domesticated rices (Oryza AA genome species) based upon whole chloroplast genome sequences. Scientific Reports 5:13957-13957.

Wang Q., Mei C., Zhen H. and Zhu, J. 2014. Codon preference optimization increases prokaryotic cystatin c expression. Journal of Biomedicine \& Biotechnology 2012(3):1-7.

Wang X., Rhein H. S., Jenkins J., Schmutz J., Grimwood J., Grauke, L. J. and Randall J.J. 2020. Chloroplast genome sequences of carya illinoinensis from two distinct geographic populations. Tree Genetics \& Genomes 16:48.

Wang Y., Li J., Fan Z., Wu D.Y., Yin H.F. and Li X.L. 2021, Characterization of the complete chloroplast genome of Camellia brevistyla, an oil-rich and evergreen shrub. Mitochondrial DNA Part B 6(8):2246-2248.

Xiong L., Li J., Li Y., Yuan L., Liu S., Huang J. and Liu Z. 2013. Dynamic changes in catechin levels and catechin biosynthesis-related gene expression in albino tea plants (Camellia sinensis L.). Plant Physiology and Biochemistry 71: 132-143.

Yu J.J., Wang H.Y., Chen D.G. and Fang Y.P., 2021, Chloroplast Genome Characteristics and Codon Usage Biases of Sinojackia huangmeiensis, a Species with Extremely Small Population, Molecular Plant Breeding 22:7189-7196.

Zhang Q., Liu M. and Ruan J. 2017. Integrated transcriptome and metabolic analyses reveal novel insights into free amino acid metabolism in Huangjinya tea cultivar. Frontiers in Plant Science 8:291. 
Table 2 Codon usage of chloroplast genome of "Huangjinya" and "Huabai 1"

\begin{tabular}{|c|c|c|c|c|c|c|c|c|}
\hline \multirow{2}{*}{ Amino acid } & \multicolumn{2}{|c|}{ Codon } & \multicolumn{2}{|c|}{ No. of codons } & \multicolumn{2}{|c|}{$\mathrm{RSCU}^{\mathrm{a}}$} & \multicolumn{2}{|c|}{ tRNA } \\
\hline & HJY & $\mathrm{HB}$ & HJY & $\mathrm{HB}$ & HJY & $\mathrm{HB}$ & HJY & $\mathrm{HB}$ \\
\hline Stop & UGA & UAA & 0 & 0 & 0 & 0 & & \\
\hline Stop & UAA & UGA & 0 & 0 & 0 & 0 & & \\
\hline Ala & GCC & GCU & 150 & 456 & 0.63 & 1.91 & & $\operatorname{trn} A-U G C$ \\
\hline Ala & GCG & $\mathrm{GCC}$ & 87 & 152 & 0.37 & 0.64 & & \\
\hline Ala & GCU & GCA & 451 & 260 & 1.91 & 1.09 & $\operatorname{trn} \mathrm{A}-\mathrm{UGC}$ & \\
\hline Ala & GCA & GCG & 257 & 86 & 1.09 & 0.36 & & \\
\hline Cys & UGU & UGU & 127 & 127 & 1.58 & 1.58 & $\operatorname{trnR}-\mathrm{UCU}$ & $\operatorname{trnR}-U C U$ \\
\hline Cys & UGC & UGC & 34 & 34 & 0.42 & 0.42 & $\operatorname{trnC}-\mathrm{GCA}$ & $\operatorname{trnC}-\mathrm{GCA}$ \\
\hline Asp & GAU & GAU & 507 & 508 & 1.64 & 1.65 & & \\
\hline Asp & GAC & GAC & 110 & 109 & 0.36 & 0.35 & & \\
\hline Glu & GAG & GAG & 205 & 207 & 0.53 & 0.53 & & \\
\hline Glu & GAA & GAA & 566 & 571 & 1.47 & 1.47 & & \\
\hline Phe & UUC & UUU & 308 & 544 & 0.72 & 1.27 & $\operatorname{trnI-GAU}$ & \\
\hline Phe & UUU & UUC & 544 & 312 & 1.28 & 0.73 & & trnI-GAU \\
\hline Gly & GGA & GGG & 441 & 180 & 1.57 & 0.64 & & \\
\hline Gly & GGU & GGA & 383 & 442 & 1.36 & 1.57 & & \\
\hline Gly & GGG & GGC & 180 & 118 & 0.64 & 0.42 & & trnG-GCC \\
\hline Gly & GGC & GGU & 120 & 386 & 0.43 & 1.37 & $\operatorname{trnG}-\mathrm{GCC}$ & \\
\hline His & CAU & CAU & 294 & 293 & 1.6 & 1.6 & & \\
\hline His & CAC & $\mathrm{CAC}$ & 73 & 73 & 0.4 & 0.4 & & \\
\hline Ile & AUC & AUC & 270 & 270 & 0.61 & 0.61 & & \\
\hline Ile & AUU & AUA & 652 & 400 & 1.48 & 0.91 & & \\
\hline Ile & AUA & AUU & 399 & 653 & 0.91 & 1.48 & & \\
\hline Lys & AAG & $\mathrm{AAG}$ & 175 & 176 & 0.5 & 0.5 & & \\
\hline Lys & AAA & AAA & 525 & 534 & 1.5 & 1.5 & & \\
\hline Leu & UUA & UUA & 517 & 522 & 1.91 & 1.91 & & \\
\hline Leu & CUG & CUA & 99 & 225 & 0.37 & 0.83 & & \\
\hline Leu & CUA & UUG & 226 & 324 & 0.83 & 1.19 & & $\operatorname{trnM}-\mathrm{CAU}$ \\
\hline Leu & CUC & CUC & 111 & 113 & 0.41 & 0.41 & $\operatorname{trnH}-\mathrm{GUG}$ & $\operatorname{trnH}-\mathrm{GUG}$ \\
\hline Leu & CUU & CUU & 351 & 355 & 1.3 & 1.3 & $\operatorname{trnL}-\mathrm{UAG}$ & $\operatorname{trnL}-\mathrm{UAG}$ \\
\hline Leu & UUG & CUG & 320 & 97 & 1.18 & 0.36 & $\operatorname{trnM}-\mathrm{CAU}$ & \\
\hline Met & AUG & AUG & 371 & 373 & 1 & 1 & & \\
\hline Asn & AAC & AAU & 176 & 512 & 0.52 & 1.49 & & \\
\hline Asn & AAU & $\mathrm{AAC}$ & 507 & 176 & 1.48 & 0.51 & & \\
\hline Pro & $\mathrm{CCU}$ & $\mathrm{CCU}$ & 280 & 280 & 1.74 & 1.74 & trnP-UGG & trnP-UGG \\
\hline Pro & CCG & $\mathrm{CCC}$ & 82 & 94 & 0.51 & 0.58 & & \\
\hline Pro & CCA & $\mathrm{CCG}$ & 189 & 82 & 1.17 & 0.51 & & \\
\hline Pro & $\mathrm{CCC}$ & $\mathrm{CCA}$ & 94 & 189 & 0.58 & 1.17 & & \\
\hline Gln & CAA & CAA & 396 & 402 & 1.49 & 1.48 & & \\
\hline Gln & CAG & $\mathrm{CAG}$ & 135 & 141 & 0.51 & 0.52 & & \\
\hline Arg & CGC & AGA & 55 & 274 & 0.36 & 1.77 & & \\
\hline
\end{tabular}




\begin{tabular}{|c|c|c|c|c|c|c|c|c|}
\hline Arg & AGG & AGG & 83 & 83 & 0.54 & 0.54 & & \\
\hline Arg & CGG & CGG & 63 & 63 & 0.41 & 0.41 & & \\
\hline Arg & CGA & CGA & 225 & 226 & 1.46 & 1.46 & & \\
\hline Arg & $\mathrm{CGU}$ & CGC & 225 & 55 & 1.46 & 0.36 & $\operatorname{trnR}-A C G$ & \\
\hline Arg & AGA & CGU & 275 & 227 & 1.78 & 1.47 & & $\operatorname{trnR}-\mathrm{ACG}$ \\
\hline Ser & UCU & AGU & 347 & 233 & 1.82 & 1.22 & $\operatorname{trnT-UGU}$ & \\
\hline Ser & UCG & UCG & 92 & 92 & 0.48 & 0.48 & & \\
\hline Ser & AGU & UCA & 234 & 215 & 1.23 & 1.12 & & \\
\hline Ser & UCC & UCU & 190 & 349 & 0.99 & 1.82 & $\operatorname{trnS-GGA}$ & $\operatorname{trnT}-\mathrm{UGU}$ \\
\hline Ser & UCA & UCC & 214 & 190 & 1.12 & 0.99 & & $\operatorname{trnS}-G G A$ \\
\hline Ser & AGC & AGC & 69 & 69 & 0.36 & 0.36 & & \\
\hline Thr & $\mathrm{ACA}$ & ACG & 225 & 74 & 1.17 & 0.38 & & \\
\hline Thr & $\mathrm{ACU}$ & $\mathrm{ACC}$ & 333 & 140 & 1.73 & 0.72 & & \\
\hline Thr & $\mathrm{ACC}$ & ACA & 138 & 225 & 0.72 & 1.16 & & \\
\hline Thr & ACG & $\mathrm{ACU}$ & 75 & 335 & 0.39 & 1.73 & & \\
\hline Val & GUU & GUG & 339 & 114 & 1.55 & 0.52 & trnE-UUC & \\
\hline Val & GUC & GUA & 88 & 336 & 0.4 & 1.54 & $\operatorname{trnV-GAC}$ & \\
\hline Val & GUG & GUU & 112 & 335 & 0.51 & 1.53 & & trnE-UUC \\
\hline Val & GUA & GUC & 337 & 88 & 1.54 & 0.4 & & $\operatorname{trnV}$-GAC \\
\hline Trp & UGG & UGG & 289 & 288 & 1 & 1 & $\operatorname{trnW}-\mathrm{CCA}$ & $\operatorname{trnW}-\mathrm{CCA}$ \\
\hline Tyr & UAU & UAU & 450 & 449 & 1.63 & 1.62 & & \\
\hline Tyr & UAC & UAC & 103 & 104 & 0.37 & 0.38 & & \\
\hline
\end{tabular}

Notes: HJY, HB refer to "Huangjinya" and "Huabai 1" respectively; a: relative synonymous codon usage, RSCU. 
Table 3 Codon usage indices of chloroplast genes in "Huangjinya"

\begin{tabular}{|c|c|c|c|c|c|c|c|c|}
\hline Title & $\mathrm{T} 3 \mathrm{~s}$ & $\mathrm{C} 3 \mathrm{~s}$ & $\mathrm{~A} 3 \mathrm{~s}$ & $\mathrm{G} 3 \mathrm{~s}$ & CAI & $\mathrm{Nc}$ & $\mathrm{GC} 3 \mathrm{~s}$ & $\mathrm{GC}$ \\
\hline HJY_rbcL & 0.5 & 0.18 & 0.39 & 0.16 & 0.28 & 47.97 & 0.27 & 0.44 \\
\hline HJY_rpl2 & 0.41 & 0.19 & 0.42 & 0.19 & 0.14 & 54.12 & 0.31 & 0.43 \\
\hline HJY_atpF & 0.31 & 0.26 & 0.38 & 0.32 & 0.16 & 55.84 & 0.44 & 0.39 \\
\hline HJY_rps19-fragment & 0.4 & 0.4 & 0.33 & 0.13 & 0.31 & - & 0.42 & 0.39 \\
\hline HJY_rpl33 & 0.47 & 0.19 & 0.44 & 0.21 & 0.16 & 52.09 & 0.29 & 0.36 \\
\hline HJY_petG & 0.45 & 0.15 & 0.41 & 0.16 & 0.16 & 56.37 & 0.25 & 0.36 \\
\hline HJY_petD & 0.35 & 0.27 & 0.32 & 0.42 & 0.17 & 54.63 & 0.48 & 0.41 \\
\hline HJY_rpl16 & 0.3 & 0.32 & 0.28 & 0.38 & 0.13 & 47.15 & 0.53 & 0.43 \\
\hline HJY_clpP & 0.48 & 0.15 & 0.47 & 0.12 & 0.21 & 48.98 & 0.22 & 0.41 \\
\hline HJY_rpl36 & 0.43 & 0.11 & 0.58 & 0.12 & 0.12 & 41.35 & 0.17 & 0.36 \\
\hline HJY_psaC & 0.53 & 0.12 & 0.45 & 0.15 & 0.18 & 55.76 & 0.21 & 0.42 \\
\hline HJY_petB & 0.44 & 0.27 & 0.26 & 0.26 & 0.17 & 58.76 & 0.41 & 0.41 \\
\hline HJY_rpl32 & 0.53 & 0.03 & 0.55 & 0.13 & 0.22 & 39.4 & 0.13 & 0.32 \\
\hline HJY_rps3 & 0.42 & 0.19 & 0.59 & 0.09 & 0.17 & 47.42 & 0.2 & 0.34 \\
\hline HJY_rps4 & 0.47 & 0.17 & 0.46 & 0.15 & 0.16 & 48.06 & 0.25 & 0.38 \\
\hline HJY_ycf4 & 0.51 & 0.16 & 0.39 & 0.17 & 0.15 & 46.89 & 0.25 & 0.38 \\
\hline HJY_ndhK & 0.5 & 0.13 & 0.46 & 0.13 & 0.16 & 48.06 & 0.21 & 0.37 \\
\hline HJY_rpoC1 & 0.47 & 0.16 & 0.46 & 0.18 & 0.15 & 50.07 & 0.26 & 0.39 \\
\hline HJY_psbK & 0.55 & 0.24 & 0.22 & 0.17 & 0.15 & 43.69 & 0.33 & 0.37 \\
\hline HJY_psaB-fragment & 0.48 & 0.17 & 0.38 & 0.18 & 0.2 & 49.69 & 0.27 & 0.41 \\
\hline HJY_rpoA & 0.49 & 0.14 & 0.48 & 0.18 & 0.15 & 48.02 & 0.23 & 0.34 \\
\hline HJY_psbT & 0.48 & 0.19 & 0.41 & 0.17 & 0.22 & - & 0.27 & 0.34 \\
\hline HJY_petN & 0.4 & 0.16 & 0.5 & 0 & 0.11 & 30.7 & 0.16 & 0.41 \\
\hline HJY_rps8 & 0.42 & 0.17 & 0.47 & 0.15 & 0.12 & 41.47 & 0.25 & 0.37 \\
\hline HJY_rps15 & 0.45 & 0.12 & 0.52 & 0.22 & 0.19 & 49.14 & 0.25 & 0.32 \\
\hline HJY_rpl14 & 0.46 & 0.15 & 0.46 & 0.16 & 0.17 & 44.21 & 0.24 & 0.4 \\
\hline HJY_rps11 & 0.47 & 0.1 & 0.45 & 0.11 & 0.14 & 47.92 & 0.18 & 0.44 \\
\hline HJY_ycf2 & 0.45 & 0.21 & 0.4 & 0.26 & 0.16 & 53.26 & 0.34 & 0.38 \\
\hline HJY_psbZ & 0.54 & 0.14 & 0.32 & 0.09 & 0.24 & 51.14 & 0.2 & 0.35 \\
\hline HJY_psbB & 0.49 & 0.17 & 0.37 & 0.16 & 0.19 & 47.41 & 0.27 & 0.44 \\
\hline HJY_petL & 0.52 & 0.1 & 0.35 & 0.15 & 0.12 & 61 & 0.2 & 0.33 \\
\hline HJY_rpoC2 & 0.45 & 0.16 & 0.46 & 0.19 & 0.14 & 49.26 & 0.27 & 0.37 \\
\hline HJY_ndhD & 0.45 & 0.15 & 0.48 & 0.12 & 0.15 & 45.95 & 0.22 & 0.35 \\
\hline HJY_atpB & 0.47 & 0.16 & 0.4 & 0.16 & 0.22 & 45.02 & 0.26 & 0.42 \\
\hline HJY_rps16 & 0.6 & 0.07 & 0.43 & 0.19 & 0.18 & 46.33 & 0.2 & 0.36 \\
\hline HJY_ndhJ & 0.51 & 0.16 & 0.38 & 0.21 & 0.15 & 51.41 & 0.28 & 0.4 \\
\hline HJY_rpl20 & 0.45 & 0.11 & 0.46 & 0.21 & 0.1 & 46.82 & 0.23 & 0.35 \\
\hline HJY_psbM & 0.57 & 0.13 & 0.42 & 0.05 & 0.24 & 47.17 & 0.15 & 0.31 \\
\hline HJY_ndhG & 0.51 & 0.11 & 0.43 & 0.13 & 0.14 & 42.88 & 0.19 & 0.33 \\
\hline HJY_accD & 0.58 & 0.17 & 0.35 & 0.2 & 0.2 & 48.22 & 0.27 & 0.35 \\
\hline HJY_ndhB & 0.43 & 0.21 & 0.43 & 0.12 & 0.16 & 46.73 & 0.27 & 0.37 \\
\hline HJY_psbJ & 0.53 & 0.13 & 0.27 & 0.15 & 0.16 & 36.11 & 0.24 & 0.4 \\
\hline HJY_pbf1 & 0.39 & 0.25 & 0.45 & 0.13 & 0.16 & 48.23 & 0.31 & 0.43 \\
\hline
\end{tabular}




\begin{tabular}{|c|c|c|c|c|c|c|c|c|}
\hline HJY_rpoB & 0.46 & 0.12 & 0.46 & 0.21 & 0.15 & 48.21 & 0.25 & 0.39 \\
\hline HJY_rps19 & 0.43 & 0.14 & 0.53 & 0.14 & 0.17 & 44.8 & 0.21 & 0.35 \\
\hline HJY_psaA-fragment & 0.51 & 0.14 & 0.38 & 0.18 & 0.17 & 48.74 & 0.26 & 0.41 \\
\hline HJY_psbI & 0.47 & 0.28 & 0.44 & 0 & 0.22 & 24.1 & 0.26 & 0.37 \\
\hline HJY_psbC & 0.46 & 0.19 & 0.4 & 0.13 & 0.19 & 43.49 & 0.27 & 0.44 \\
\hline HJY_atpE & 0.5 & 0.13 & 0.39 & 0.2 & 0.16 & 46.05 & 0.25 & 0.39 \\
\hline HJY_ycf1 & 0.48 & 0.16 & 0.56 & 0.16 & 0.16 & 46.45 & 0.22 & 0.3 \\
\hline HJY_cemA & 0.51 & 0.21 & 0.42 & 0.16 & 0.19 & 49.65 & 0.27 & 0.32 \\
\hline HJY_psbF & 0.32 & 0.18 & 0.47 & 0.19 & 0.13 & 55.4 & 0.31 & 0.44 \\
\hline HJY_psaA & 0.46 & 0.19 & 0.4 & 0.16 & 0.2 & 49.2 & 0.28 & 0.43 \\
\hline HJY_ndhE & 0.56 & 0.12 & 0.36 & 0.15 & 0.17 & 41.09 & 0.21 & 0.32 \\
\hline HJY_rps2 & 0.48 & 0.14 & 0.44 & 0.17 & 0.18 & 47.47 & 0.24 & 0.38 \\
\hline HJY_psaJ & 0.4 & 0.1 & 0.52 & 0.21 & 0.14 & 45.04 & 0.24 & 0.36 \\
\hline HJY_psbH & 0.53 & 0.03 & 0.4 & 0.19 & 0.13 & 41.35 & 0.18 & 0.36 \\
\hline HJY_psaB & 0.51 & 0.16 & 0.37 & 0.17 & 0.19 & 47.67 & 0.26 & 0.41 \\
\hline HJY_ndhC & 0.54 & 0.1 & 0.43 & 0.14 & 0.2 & 45.99 & 0.18 & 0.35 \\
\hline HJY_rpl23 & 0.47 & 0.12 & 0.44 & 0.19 & 0.13 & 49.8 & 0.24 & 0.38 \\
\hline HJY_atpA & 0.51 & 0.14 & 0.43 & 0.14 & 0.21 & 43.04 & 0.22 & 0.4 \\
\hline HJY_ndhF & 0.55 & 0.1 & 0.42 & 0.14 & 0.14 & 41.78 & 0.18 & 0.32 \\
\hline HJY_ccsA & 0.48 & 0.14 & 0.5 & 0.11 & 0.15 & 46.52 & 0.2 & 0.32 \\
\hline HJY_rpl22 & 0.47 & 0.15 & 0.54 & 0.12 & 0.17 & 43 & 0.2 & 0.35 \\
\hline HJY_petA & 0.51 & 0.16 & 0.39 & 0.2 & 0.19 & 48.63 & 0.27 & 0.39 \\
\hline HJY_rps18 & 0.5 & 0.11 & 0.41 & 0.2 & 0.11 & 35.64 & 0.24 & 0.35 \\
\hline HJY_ndhA & 0.47 & 0.12 & 0.48 & 0.1 & 0.13 & 41.33 & 0.18 & 0.34 \\
\hline HJY_infA & 0.52 & 0.13 & 0.42 & 0.16 & 0.13 & 54.48 & 0.22 & 0.37 \\
\hline HJY_atpI & 0.49 & 0.18 & 0.4 & 0.12 & 0.17 & 44.59 & 0.24 & 0.38 \\
\hline HJY_ndhI & 0.5 & 0.18 & 0.46 & 0.16 & 0.18 & 49.59 & 0.25 & 0.36 \\
\hline HJY_psbA & 0.53 & 0.25 & 0.31 & 0.07 & 0.32 & 40.6 & 0.28 & 0.42 \\
\hline HJY_rps7 & 0.43 & 0.13 & 0.52 & 0.12 & 0.19 & 45.81 & 0.2 & 0.4 \\
\hline HJY_psbE & 0.45 & 0.25 & 0.37 & 0.11 & 0.16 & 45.58 & 0.3 & 0.42 \\
\hline HJY_atpH & 0.52 & 0.08 & 0.33 & 0.18 & 0.18 & 49.16 & 0.23 & 0.46 \\
\hline HJY_ycf1-fragment & 0.45 & 0.18 & 0.54 & 0.17 & 0.16 & 49.01 & 0.25 & 0.33 \\
\hline HJY_rps14 & 0.38 & 0.12 & 0.49 & 0.25 & 0.13 & 37.46 & 0.29 & 0.41 \\
\hline HJY_rps12-fragment & 0.41 & 0.16 & 0.41 & 0.21 & 0.1 & 43 & 0.3 & 0.45 \\
\hline HJY_psbD & 0.51 & 0.21 & 0.36 & 0.11 & 0.25 & 43.45 & 0.27 & 0.42 \\
\hline HJY_matK & 0.5 & 0.16 & 0.45 & 0.18 & 0.16 & 47.2 & 0.25 & 0.33 \\
\hline HJY_ndhH & 0.3 & 0.29 & 0.37 & 0.38 & 0.17 & 57.65 & 0.48 & 0.38 \\
\hline HJY_ycf3 & 0.47 & 0.16 & 0.47 & 0.21 & 0.15 & 56.67 & 0.27 & 0.39 \\
\hline HJY_psbL & 0.44 & 0.28 & 0.42 & 0.13 & 0.19 & 47.54 & 0.33 & 0.33 \\
\hline HJY_rps12 & 0.33 & 0.28 & 0.39 & 0.29 & 0.12 & 54.93 & 0.44 & 0.44 \\
\hline HJY_psaI & 0.54 & 0.14 & 0.4 & 0.09 & 0.27 & 35.75 & 0.19 & 0.35 \\
\hline
\end{tabular}


Table 4 Codon usage indices of genes in chloroplast of "Huabai 1"

\begin{tabular}{|c|c|c|c|c|c|c|c|c|}
\hline Title & $\mathrm{T} 3 \mathrm{~s}$ & $\mathrm{C} 3 \mathrm{~s}$ & $\mathrm{~A} 3 \mathrm{~s}$ & G3s & CAI & $\mathrm{Nc}$ & $\mathrm{GC} 3 \mathrm{~s}$ & $\mathrm{GC}$ \\
\hline HB_psbZ & 0.54 & 0.14 & 0.32 & 0.09 & 0.24 & 51.14 & 0.2 & 0.35 \\
\hline HB_rpoA & 0.49 & 0.14 & 0.48 & 0.19 & 0.15 & 48.47 & 0.24 & 0.34 \\
\hline HB_rps14 & 0.38 & 0.12 & 0.49 & 0.25 & 0.13 & 37.46 & 0.29 & 0.41 \\
\hline HB_psbM & 0.57 & 0.13 & 0.42 & 0.05 & 0.24 & 47.17 & 0.15 & 0.31 \\
\hline HB_rps19 & 0.43 & 0.14 & 0.53 & 0.14 & 0.17 & 44.8 & 0.21 & 0.35 \\
\hline HB_ndhA & 0.47 & 0.12 & 0.48 & 0.1 & 0.13 & 41.33 & 0.18 & 0.34 \\
\hline HB_matK & 0.5 & 0.16 & 0.45 & 0.18 & 0.16 & 46.99 & 0.25 & 0.33 \\
\hline HB_rps8 & 0.42 & 0.17 & 0.47 & 0.15 & 0.12 & 41.44 & 0.25 & 0.37 \\
\hline HB_petD & 0.35 & 0.27 & 0.32 & 0.42 & 0.17 & 54.63 & 0.48 & 0.41 \\
\hline HB_rpoC1 & 0.47 & 0.16 & 0.46 & 0.18 & 0.15 & 50.07 & 0.26 & 0.39 \\
\hline HB_ndhF & 0.55 & 0.1 & 0.42 & 0.14 & 0.14 & 41.78 & 0.18 & 0.32 \\
\hline HB_rpl14 & 0.46 & 0.15 & 0.46 & 0.16 & 0.17 & 44.21 & 0.24 & 0.4 \\
\hline HB_ndhJ & 0.51 & 0.16 & 0.38 & 0.21 & 0.15 & 51.41 & 0.28 & 0.4 \\
\hline HB_rps16 & 0.61 & 0.08 & 0.43 & 0.19 & 0.18 & 45.41 & 0.2 & 0.36 \\
\hline HB_atpA & 0.51 & 0.14 & 0.43 & 0.14 & 0.21 & 43.04 & 0.22 & 0.4 \\
\hline HB_psbK & 0.55 & 0.24 & 0.22 & 0.17 & 0.15 & 43.69 & 0.33 & 0.37 \\
\hline HB_ycf4 & 0.51 & 0.17 & 0.39 & 0.17 & 0.15 & 46.77 & 0.26 & 0.38 \\
\hline HB_ndhD & 0.45 & 0.15 & 0.48 & 0.12 & 0.15 & 45.95 & 0.22 & 0.35 \\
\hline HB_rps11 & 0.47 & 0.1 & 0.45 & 0.11 & 0.14 & 47.92 & 0.18 & 0.44 \\
\hline HB_ndhE & 0.56 & 0.12 & 0.36 & 0.15 & 0.17 & 41.09 & 0.21 & 0.32 \\
\hline HB_rpl20 & 0.45 & 0.11 & 0.46 & 0.21 & 0.1 & 46.82 & 0.23 & 0.35 \\
\hline HB_ndhK & 0.5 & 0.13 & 0.46 & 0.13 & 0.16 & 48.06 & 0.21 & 0.37 \\
\hline HB_atpE & 0.5 & 0.13 & 0.39 & 0.2 & 0.16 & 46.05 & 0.25 & 0.39 \\
\hline HB_ndhI & 0.5 & 0.18 & 0.46 & 0.16 & 0.18 & 49.59 & 0.25 & 0.36 \\
\hline HB_ndhB & 0.43 & 0.21 & 0.43 & 0.12 & 0.16 & 46.73 & 0.27 & 0.37 \\
\hline HB_rps7 & 0.43 & 0.13 & 0.52 & 0.12 & 0.19 & 45.81 & 0.2 & 0.4 \\
\hline HB_rps4 & 0.47 & 0.17 & 0.47 & 0.14 & 0.16 & 47.88 & 0.24 & 0.38 \\
\hline HB_atpB & 0.47 & 0.16 & 0.4 & 0.16 & 0.22 & 45.02 & 0.26 & 0.42 \\
\hline HB_psaA-fragment & 0.51 & 0.14 & 0.38 & 0.18 & 0.17 & 48.74 & 0.26 & 0.41 \\
\hline HB_psbF & 0.32 & 0.18 & 0.47 & 0.19 & 0.13 & 55.4 & 0.31 & 0.44 \\
\hline HB_psbE & 0.45 & 0.25 & 0.37 & 0.11 & 0.16 & 45.58 & 0.3 & 0.42 \\
\hline HB_psbL & 0.44 & 0.28 & 0.42 & 0.13 & 0.19 & 47.54 & 0.33 & 0.33 \\
\hline HB_psbA & 0.53 & 0.25 & 0.31 & 0.07 & 0.32 & 40.6 & 0.28 & 0.42 \\
\hline HB_rpl2 & 0.41 & 0.19 & 0.42 & 0.19 & 0.14 & 54.12 & 0.31 & 0.43 \\
\hline HB_petB & 0.44 & 0.27 & 0.26 & 0.26 & 0.17 & 58.76 & 0.41 & 0.41 \\
\hline HB_rpl23 & 0.47 & 0.12 & 0.44 & 0.19 & 0.13 & 49.8 & 0.24 & 0.38 \\
\hline HB_psbD & 0.51 & 0.21 & 0.36 & 0.11 & 0.25 & 43.45 & 0.27 & 0.42 \\
\hline HB_petG & 0.45 & 0.15 & 0.41 & 0.16 & 0.16 & 56.37 & 0.25 & 0.36 \\
\hline HB_petN & 0.4 & 0.16 & 0.5 & 0 & 0.11 & 30.7 & 0.16 & 0.41 \\
\hline HB_petL & 0.52 & 0.1 & 0.35 & 0.15 & 0.12 & 61 & 0.2 & 0.33 \\
\hline HB_psbH & 0.53 & 0.03 & 0.4 & 0.19 & 0.13 & 41.35 & 0.18 & 0.36 \\
\hline HB_rps12 & 0.33 & 0.28 & 0.39 & 0.29 & 0.12 & 54.93 & 0.44 & 0.44 \\
\hline HB_rps 18 & 0.5 & 0.11 & 0.41 & 0.2 & 0.11 & 35.64 & 0.24 & 0.35 \\
\hline
\end{tabular}




\begin{tabular}{|c|c|c|c|c|c|c|c|c|}
\hline HB_psbB & 0.49 & 0.17 & 0.37 & 0.16 & 0.19 & 47.41 & 0.27 & 0.44 \\
\hline HB_atpI & 0.49 & 0.18 & 0.4 & 0.12 & 0.17 & 44.59 & 0.24 & 0.38 \\
\hline HB_ycf3 & 0.47 & 0.16 & 0.47 & 0.21 & 0.15 & 56.67 & 0.27 & 0.39 \\
\hline HB_psbT & 0.48 & 0.19 & 0.41 & 0.17 & 0.22 & $* * * * *$ & 0.27 & 0.34 \\
\hline HB_psaC & 0.53 & 0.12 & 0.45 & 0.15 & 0.18 & 55.76 & 0.21 & 0.42 \\
\hline HB_ccsA & 0.48 & 0.14 & 0.5 & 0.11 & 0.15 & 46.52 & 0.2 & 0.32 \\
\hline HB_cemA & 0.51 & 0.21 & 0.42 & 0.16 & 0.19 & 49.65 & 0.27 & 0.32 \\
\hline HB_infA & 0.52 & 0.13 & 0.42 & 0.16 & 0.13 & 54.48 & 0.22 & 0.37 \\
\hline HB_petA & 0.51 & 0.16 & 0.39 & 0.2 & 0.19 & 48.63 & 0.27 & 0.39 \\
\hline HB_psaB-fragment & 0.48 & 0.17 & 0.38 & 0.18 & 0.2 & 49.69 & 0.27 & 0.41 \\
\hline HB_psbJ & 0.53 & 0.13 & 0.27 & 0.15 & 0.16 & 36.11 & 0.24 & 0.4 \\
\hline HB_rbcL & 0.5 & 0.18 & 0.39 & 0.16 & 0.28 & 47.97 & 0.27 & 0.44 \\
\hline HB_ndhH & 0.3 & 0.29 & 0.37 & 0.38 & 0.17 & 56.39 & 0.48 & 0.38 \\
\hline HB_atpF & 0.31 & 0.26 & 0.38 & 0.32 & 0.16 & 55.84 & 0.44 & 0.39 \\
\hline HB_psaJ & 0.4 & 0.1 & 0.52 & 0.21 & 0.14 & 45.04 & 0.24 & 0.36 \\
\hline HB_rpl16 & 0.3 & 0.32 & 0.28 & 0.38 & 0.13 & 47.15 & 0.53 & 0.43 \\
\hline HB_rpl36 & 0.43 & 0.11 & 0.58 & 0.12 & 0.12 & 41.35 & 0.17 & 0.36 \\
\hline HB_ndhC & 0.54 & 0.1 & 0.43 & 0.14 & 0.2 & 45.99 & 0.18 & 0.35 \\
\hline HB_ycf2 & 0.45 & 0.21 & 0.4 & 0.26 & 0.16 & 53.26 & 0.34 & 0.38 \\
\hline HB_psbC & 0.46 & 0.19 & 0.4 & 0.13 & 0.19 & 43.49 & 0.27 & 0.44 \\
\hline HB_rps19-fragment & 0.4 & 0.4 & 0.33 & 0.13 & 0.31 & $* * * * *$ & 0.42 & 0.39 \\
\hline HB_rpl33 & 0.47 & 0.19 & 0.44 & 0.21 & 0.16 & 52.09 & 0.29 & 0.36 \\
\hline HB_clpP & 0.48 & 0.15 & 0.47 & 0.12 & 0.21 & 49.9 & 0.22 & 0.41 \\
\hline HB_rpl32 & 0.53 & 0.03 & 0.55 & 0.13 & 0.22 & 39.4 & 0.13 & 0.32 \\
\hline HB_pbfl & 0.39 & 0.25 & 0.45 & 0.13 & 0.16 & 48.23 & 0.31 & 0.43 \\
\hline HB_psbI & 0.47 & 0.28 & 0.44 & 0 & 0.22 & 24.1 & 0.26 & 0.37 \\
\hline HB_rps2 & 0.48 & 0.14 & 0.44 & 0.17 & 0.18 & 47.47 & 0.24 & 0.38 \\
\hline HB_ycf1-fragment & 0.41 & 0.24 & 0.45 & 0.2 & 0.17 & 57.22 & 0.33 & 0.36 \\
\hline HB_rpoB & 0.46 & 0.12 & 0.46 & 0.21 & 0.15 & 48.21 & 0.25 & 0.39 \\
\hline HB_psaI & 0.54 & 0.14 & 0.4 & 0.09 & 0.27 & 35.75 & 0.19 & 0.35 \\
\hline HB_rpl22 & 0.47 & 0.15 & 0.54 & 0.12 & 0.17 & 43 & 0.2 & 0.35 \\
\hline HB_ycf1 & 0.48 & 0.16 & 0.56 & 0.16 & 0.16 & 46.55 & 0.22 & 0.3 \\
\hline HB_psaA & 0.46 & 0.19 & 0.4 & 0.16 & 0.2 & 49.2 & 0.28 & 0.43 \\
\hline HB_rps15 & 0.45 & 0.12 & 0.52 & 0.22 & 0.19 & 49.14 & 0.25 & 0.32 \\
\hline HB_ndhG & 0.51 & 0.11 & 0.43 & 0.13 & 0.14 & 42.88 & 0.19 & 0.33 \\
\hline HB_accD & 0.58 & 0.17 & 0.35 & 0.2 & 0.2 & 48.21 & 0.27 & 0.35 \\
\hline HB_rpoC2 & 0.45 & 0.16 & 0.46 & 0.19 & 0.14 & 49.17 & 0.27 & 0.37 \\
\hline HB_rps12-fragment & 0.41 & 0.16 & 0.41 & 0.21 & 0.1 & 43 & 0.3 & 0.45 \\
\hline HB_rps3 & 0.42 & 0.19 & 0.59 & 0.09 & 0.17 & 47.42 & 0.2 & 0.34 \\
\hline HB_atpH & 0.52 & 0.08 & 0.33 & 0.18 & 0.18 & 49.16 & 0.23 & 0.46 \\
\hline HB_psaB & 0.51 & 0.16 & 0.37 & 0.17 & 0.19 & 47.67 & 0.26 & 0.41 \\
\hline
\end{tabular}


Table 5 SSR analysis of "Huangjinya" and "Huabai 1" chloroplast genome

\begin{tabular}{|c|c|c|c|c|c|c|c|c|c|c|}
\hline \multirow[b]{2}{*}{ No. } & \multicolumn{5}{|c|}{ Huangjinya } & \multicolumn{5}{|c|}{ Huabai 1} \\
\hline & Type & SSR & $\begin{array}{l}\text { Size } \\
\text { (bp) }\end{array}$ & Start & End & Type & SSR & $\begin{array}{l}\text { Size } \\
\text { (bp) }\end{array}$ & Start & End \\
\hline 1 & Mon & $(\mathrm{A})_{10}$ & 10 & 3791 & 3800 & Mon & $(\mathrm{A})_{10}$ & 10 & 3791 & 3800 \\
\hline 2 & Mon & $(\mathrm{A})_{10}$ & 10 & 8904 & 8913 & Mon & $(\mathrm{A})_{10}$ & 10 & 65314 & 65323 \\
\hline 3 & Mon & $(\mathrm{A})_{10}$ & 10 & 32930 & 32939 & Mon & $(\mathrm{A})_{10}$ & 10 & 73238 & 73247 \\
\hline 4 & Mon & $(\mathrm{A})_{10}$ & 10 & 65330 & 65339 & Mon & $(\mathrm{A})_{10}$ & 10 & 128318 & 128327 \\
\hline 5 & Mon & $(\mathrm{A})_{10}$ & 10 & 73302 & 73311 & Mon & $(\mathrm{A})_{10}$ & 10 & 129797 & 129806 \\
\hline 6 & Mon & $(\mathrm{A})_{10}$ & 10 & 82858 & 82867 & Mon & $(\mathrm{A})_{10}$ & 10 & 138306 & 138315 \\
\hline 7 & Mon & $(\mathrm{A})_{10}$ & 10 & 131686 & 131695 & Mon & $(\mathrm{A})_{11}$ & 11 & 8909 & 8919 \\
\hline 8 & Mon & $(\mathrm{A})_{10}$ & 10 & 140204 & 140213 & Mon & $(\mathrm{A})_{11}$ & 11 & 17281 & 17291 \\
\hline 9 & Mon & $(\mathrm{A})_{11}$ & 11 & 17271 & 17281 & Mon & $(\mathrm{A})_{11}$ & 11 & 32935 & 32945 \\
\hline 10 & Mon & $(\mathrm{A})_{11}$ & 11 & 34201 & 34211 & Mon & $(\mathrm{A})_{11}$ & 11 & 34216 & 34226 \\
\hline 11 & Mon & $(\mathrm{A})_{11}$ & 11 & 38261 & 38271 & Mon & $(\mathrm{A})_{11}$ & 11 & 38277 & 38287 \\
\hline 12 & Mon & $(\mathrm{A})_{11}$ & 11 & 46229 & 46239 & Mon & $(\mathrm{A})_{11}$ & 11 & 46245 & 46255 \\
\hline 13 & Mon & $(\mathrm{A})_{11}$ & 11 & 83627 & 83637 & Mon & $(\mathrm{A})_{11}$ & 11 & 83563 & 83573 \\
\hline 14 & Mon & $(\mathrm{A})_{11}$ & 11 & 110415 & 110425 & Mon & $(\mathrm{A})_{11}$ & 11 & 110361 & 110371 \\
\hline 15 & Mon & $(\mathrm{A})_{11}$ & 11 & 117891 & 117901 & Mon & $(\mathrm{A})_{11}$ & 11 & 116009 & 116019 \\
\hline 16 & Mon & $(\mathrm{A})_{11}$ & 11 & 119067 & 119077 & Mon & $(\mathrm{A})_{11}$ & 11 & 117185 & 117195 \\
\hline 17 & Mon & $(\mathrm{A})_{12}$ & 12 & 32596 & 32607 & Mon & $(\mathrm{A})_{12}$ & 12 & 38510 & 38521 \\
\hline 18 & Mon & $(\mathrm{A})_{12}$ & 12 & 38494 & 38505 & Mon & $(\mathrm{A})_{13}$ & 12 & 129264 & 129275 \\
\hline 19 & Mon & $(\mathrm{A})_{12}$ & 12 & 49310 & 49321 & Mon & $(\mathrm{A})_{13}$ & 13 & 356 & 368 \\
\hline 20 & Mon & $(\mathrm{A})_{12}$ & 12 & 131153 & 131164 & Mon & $(\mathrm{A})_{13}$ & 13 & 32600 & 32612 \\
\hline 21 & Mon & $(\mathrm{A})_{13}$ & 13 & 356 & 368 & Mon & $(\mathrm{A})_{13}$ & 13 & 46500 & 46512 \\
\hline 22 & Mon & $(\mathrm{A})_{13}$ & 13 & 37621 & 37633 & Mon & $(\mathrm{A})_{13}$ & 13 & 49326 & 49338 \\
\hline 23 & Mon & $(\mathrm{A})_{13}$ & 13 & 46484 & 46496 & Mon & $(\mathrm{A})_{14}$ & 14 & 37636 & 37649 \\
\hline 24 & Mon & $(\mathrm{A})_{16}$ & 16 & 12554 & 12569 & Mon & $(\mathrm{A})_{17}$ & 17 & 12557 & 12573 \\
\hline 25 & Mon & $(\mathrm{A})_{17}$ & 17 & 113487 & 113503 & Mon & $(\mathrm{T})_{10}$ & 10 & 27181 & 27190 \\
\hline 26 & Mon & $(\mathrm{C})_{10}$ & 10 & 10968 & 10977 & Mon & $(\mathrm{T})_{10}$ & 10 & 37236 & 37245 \\
\hline 27 & Mon & $(\mathrm{T})_{10}$ & 10 & 6390 & 6399 & Mon & $(\mathrm{T})_{10}$ & 10 & 56325 & 56334 \\
\hline 28 & Mon & $(\mathrm{T})_{10}$ & 10 & 27177 & 27186 & Mon & $(\mathrm{T})_{10}$ & 10 & 65452 & 65461 \\
\hline 29 & Mon & $(\mathrm{T})_{10}$ & 10 & 37221 & 37230 & Mon & $(\mathrm{T})_{10}$ & 10 & 65768 & 65777 \\
\hline 30 & Mon & $(\mathrm{T})_{10}$ & 10 & 56308 & 56317 & Mon & $(\mathrm{T})_{10}$ & 10 & 70907 & 70916 \\
\hline 31 & Mon & $(\mathrm{T})_{10}$ & 10 & 63155 & 63164 & Mon & $(\mathrm{T})_{10}$ & 10 & 80588 & 80597 \\
\hline 32 & Mon & $(\mathrm{T})_{10}$ & 10 & 65468 & 65477 & Mon & $(\mathrm{T})_{10}$ & 10 & 82510 & 82519 \\
\hline 33 & Mon & $(\mathrm{T})_{10}$ & 10 & 65784 & 65793 & Mon & $(\mathrm{T})_{10}$ & 10 & 105303 & 105312 \\
\hline 34 & Mon & $(\mathrm{T})_{10}$ & 10 & 70971 & 70980 & Mon & $(\mathrm{T})_{11}$ & 11 & 19487 & 19497 \\
\hline 35 & Mon & $(\mathrm{T})_{10}$ & 10 & 80652 & 80661 & Mon & $(\mathrm{T})_{11}$ & 11 & 52626 & 52636 \\
\hline 36 & Mon & $(\mathrm{T})_{10}$ & 10 & 82574 & 82583 & Mon & $(\mathrm{T})_{11}$ & 11 & 58973 & 58983 \\
\hline 37 & Mon & $(\mathrm{T})_{10}$ & 10 & 105357 & 105366 & Mon & $(\mathrm{T})_{11}$ & 11 & 133247 & 133257 \\
\hline 38 & Mon & $(\mathrm{T})_{10}$ & 10 & 113875 & 113884 & Mon & $(\mathrm{T})_{12}$ & 12 & 8765 & 8776 \\
\hline 39 & Mon & $(\mathrm{T})_{10}$ & 10 & 124960 & 124969 & Mon & $(\mathrm{T})_{10}$ & 12 & 13935 & 13946 \\
\hline
\end{tabular}




\begin{tabular}{|c|c|c|c|c|c|c|c|c|c|c|}
\hline 40 & Mon & $(\mathrm{T})_{11}$ & 11 & 19477 & 19487 & Mon & $(\mathrm{T})_{12}$ & 12 & 15067 & 15078 \\
\hline 41 & Mon & $(\mathrm{T})_{11}$ & 11 & 33233 & 33243 & Mon & $(\mathrm{T})_{12}$ & 12 & 15461 & 15472 \\
\hline 42 & Mon & $(\mathrm{T})_{11}$ & 11 & 52609 & 52619 & Mon & $(\mathrm{T})_{12}$ & 12 & 33239 & 33250 \\
\hline 43 & Mon & $(\mathrm{T})_{11}$ & 11 & 58959 & 58969 & Mon & $(\mathrm{T})_{12}$ & 12 & 56759 & 56770 \\
\hline 44 & Mon & $(\mathrm{T})_{11}$ & 11 & 135145 & 135155 & Mon & $(\mathrm{T})_{12}$ & 12 & 127345 & 127356 \\
\hline 45 & Mon & $(\mathrm{T})_{12}$ & 12 & 8760 & 8771 & Mon & $(\mathrm{T})_{12}$ & 12 & 128960 & 128971 \\
\hline 46 & Mon & $(\mathrm{T})_{12}$ & 12 & 13931 & 13942 & Mon & $(\mathrm{T})_{13}$ & 13 & 85013 & 85025 \\
\hline 47 & Mon & $(\mathrm{T})_{12}$ & 12 & 15063 & 15074 & Mon & $(\mathrm{T})_{13}$ & 13 & 115371 & 115383 \\
\hline 48 & Mon & $(\mathrm{T})_{12}$ & 12 & 15451 & 15462 & Mon & $(\mathrm{T})_{14}$ & 14 & 53363 & 53376 \\
\hline 49 & Mon & $(\mathrm{T})_{12}$ & 12 & 114406 & 114417 & Mon & $(\mathrm{T})_{14}$ & 14 & 60751 & 60764 \\
\hline 50 & Mon & $(\mathrm{T})_{12}$ & 12 & 129234 & 129245 & Mon & $(\mathrm{T})_{14}$ & 14 & 121384 & 121397 \\
\hline 51 & Mon & $(\mathrm{T})_{12}$ & 12 & 130849 & 130860 & Mon & $(\mathrm{T})_{15}$ & 15 & 83035 & 83049 \\
\hline 52 & Mon & $(\mathrm{T})_{13}$ & 13 & 85077 & 85089 & Mon & $(\mathrm{T})_{17}$ & 17 & 130178 & 130194 \\
\hline 53 & Mon & $(\mathrm{T})_{13}$ & 13 & 117253 & 117265 & dimer & $(\mathrm{AT})_{5}$ & 5 & 20854 & 20863 \\
\hline 54 & Mon & $(\mathrm{T})_{14}$ & 14 & 53346 & 53359 & dimer & $(\mathrm{AT})_{5}$ & 5 & 84276 & 84285 \\
\hline 55 & Mon & $(\mathrm{T})_{14}$ & 14 & 60737 & 60750 & dimer & $(\mathrm{TA})_{5}$ & 5 & 87246 & 87255 \\
\hline 56 & Mon & $(\mathrm{T})_{14}$ & 14 & 123266 & 123279 & dimer & $(\mathrm{AT})_{5}$ & 5 & 156362 & 156371 \\
\hline 57 & Mon & $(\mathrm{T})_{15}$ & 15 & 56742 & 56756 & & & & & \\
\hline 58 & Mon & $(\mathrm{T})_{15}$ & 15 & 83099 & 83113 & & & & & \\
\hline 59 & Mon & $(\mathrm{T})_{17}$ & 17 & 132067 & 132083 & & & & & \\
\hline 60 & dimer & $(\mathrm{AT})_{5}$ & 5 & 20850 & 20859 & & & & & \\
\hline 61 & dimer & $(\mathrm{AT})_{5}$ & 5 & 84340 & 84349 & & & & & \\
\hline 62 & dimer & $(\mathrm{TA})_{5}$ & 5 & 87310 & 87319 & & & & & \\
\hline 63 & dimer & $(\mathrm{AT})_{5}$ & 5 & 158250 & 158259 & & & & & \\
\hline
\end{tabular}


Table 1 Position, exon and intron information of genes in chloroplast genome of "Huangjinya"and "Huabai 1"

\begin{tabular}{|c|c|c|c|c|c|c|c|c|c|c|c|c|}
\hline \multirow[t]{2}{*}{ Gene } & \multicolumn{2}{|c|}{ Location } & \multicolumn{2}{|c|}{ Exon I (bp) } & \multicolumn{2}{|c|}{ Intron I (bp) } & \multicolumn{2}{|c|}{ Exon II (bp) } & \multicolumn{2}{|c|}{$\begin{array}{c}\text { Intron II } \\
\text { (bp) }\end{array}$} & \multicolumn{2}{|c|}{$\begin{array}{c}\text { Exon III } \\
\text { (bp) }\end{array}$} \\
\hline & HJY & HB & HJY & HB & HJY & HB & HJY & HB & HJY & HB & HJY & HB \\
\hline $\begin{array}{l}\text { trnA- } \\
\text { UGC }\end{array}$ & IR & IR & 36 & 36 & 41 & 41 & 27 & 27 & & & & \\
\hline $\operatorname{rps} 16$ & LSC & LSC & 35 & 35 & 856 & 855 & 230 & 230 & & & & \\
\hline $\operatorname{atpF}$ & LSC & LSC & 143 & 143 & 718 & 718 & 409 & 409 & & & & \\
\hline $\mathrm{rps} 12$ & IR & IR & 231 & 231 & 537 & 537 & 26 & 26 & & & & \\
\hline clpP & LSC & LSC & 70 & 70 & 794 & 794 & 291 & 291 & 597 & 597 & 227 & 227 \\
\hline ndhA & $\mathrm{SSC}$ & SSC & 551 & 551 & 1086 & 1085 & 539 & 539 & & & & \\
\hline ycf3 & LSC & LSC & 123 & 123 & 720 & 720 & 227 & 227 & 738 & 738 & 154 & 154 \\
\hline ndhB & IR & IR & 776 & 776 & 680 & 680 & 755 & 755 & & & & \\
\hline $\mathrm{rp} 12$ & IR & IR & 390 & 390 & 671 & 671 & 433 & 433 & & & & \\
\hline trnI-GAU & IR & IR & 35 & 35 & 17 & 17 & 35 & 35 & & & & \\
\hline rpoC1 & LSC & LSC & 431 & 431 & 745 & 745 & 1616 & 1616 & & & & \\
\hline
\end{tabular}

Notes: HJY, HB refer to "Huangjinya" and "Huabai 1" respectively. 


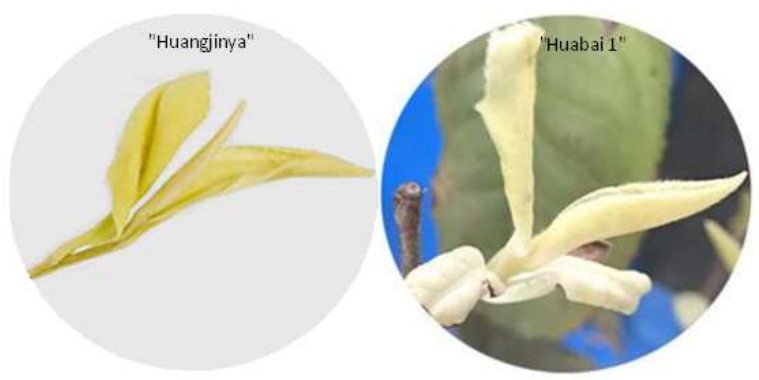

Fig.1 The leaves phenotype of "Huangjinya" and "Huabai 1" 


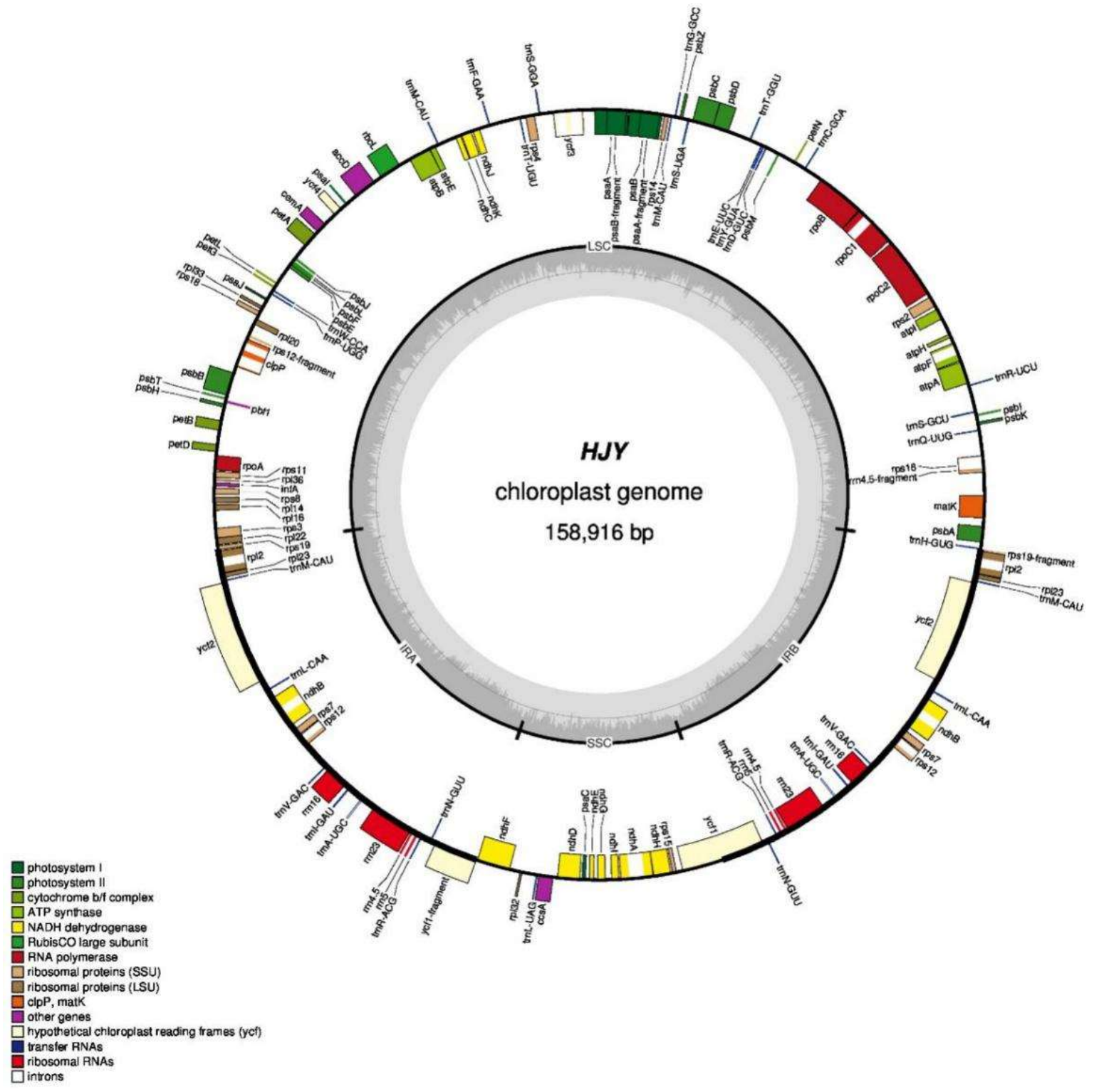

Fig. 2 Structure of chloroplast genome map of "Huangjinya" 


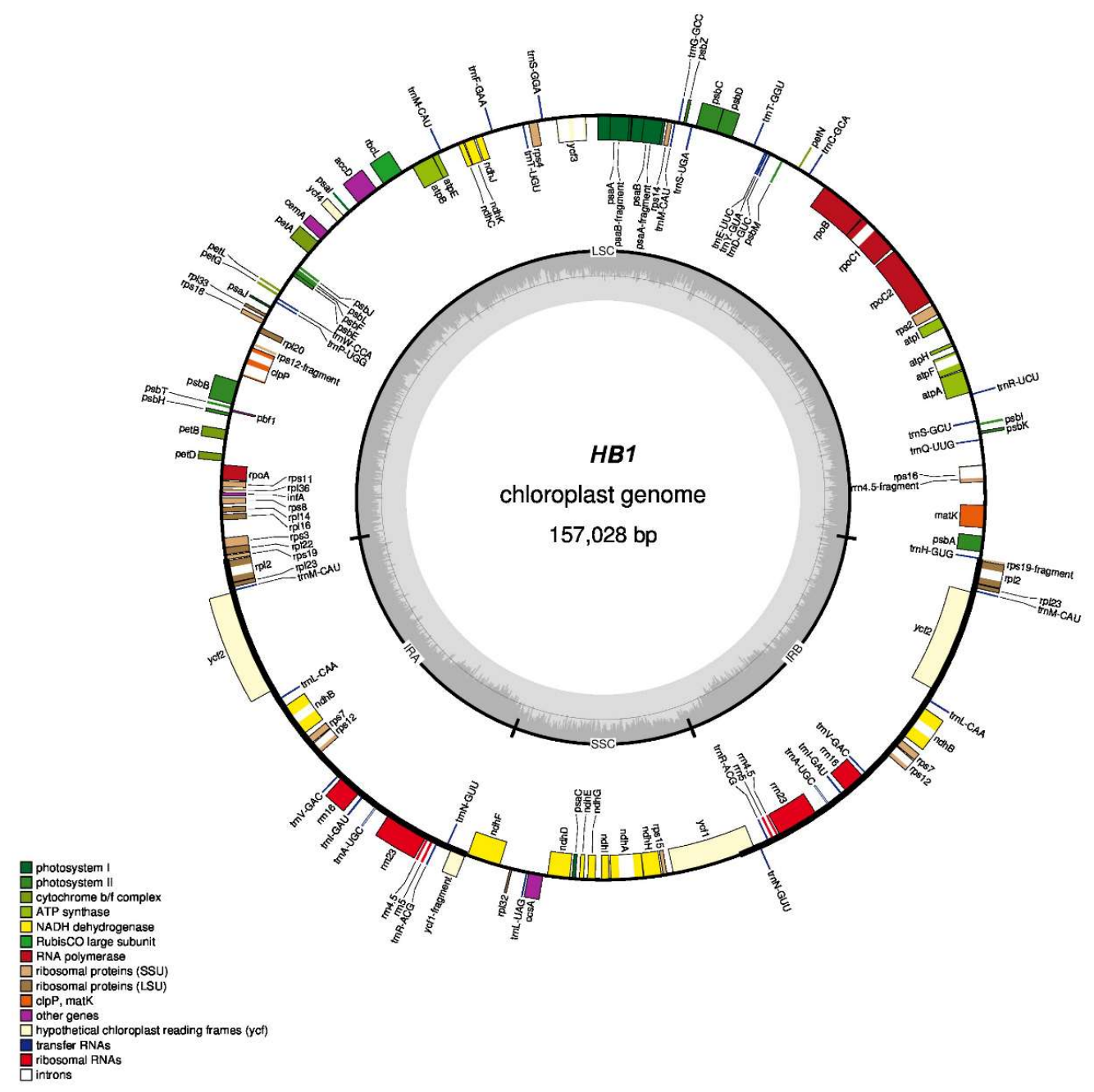

Fig. 3 Structure of chloroplast genome map of "Huabai 1" 
matK
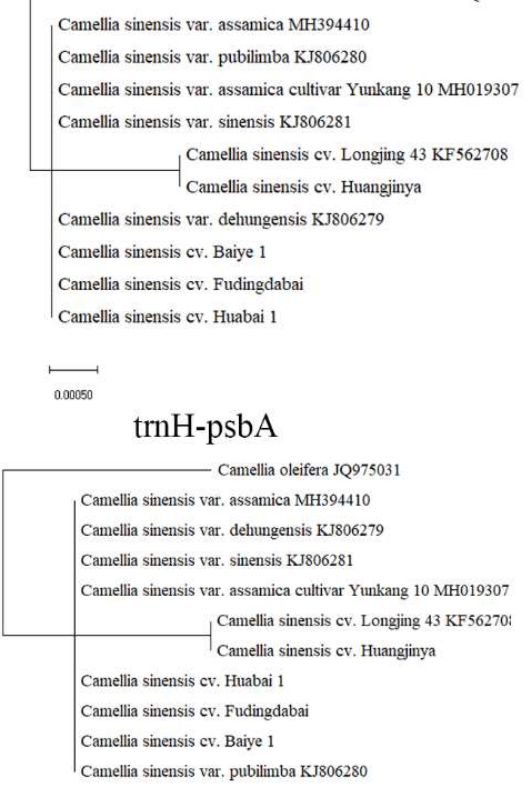

$\mathrm{rbcL}$

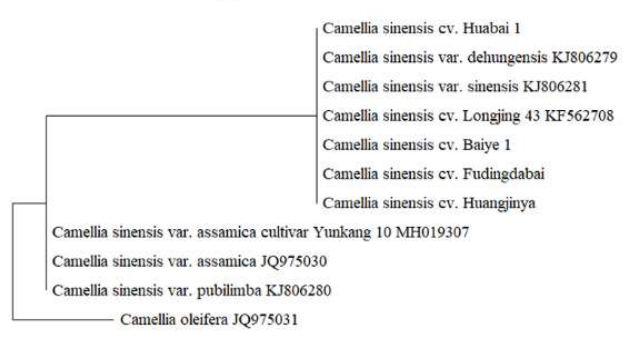

$\underset{0.000000}{\longmapsto}$

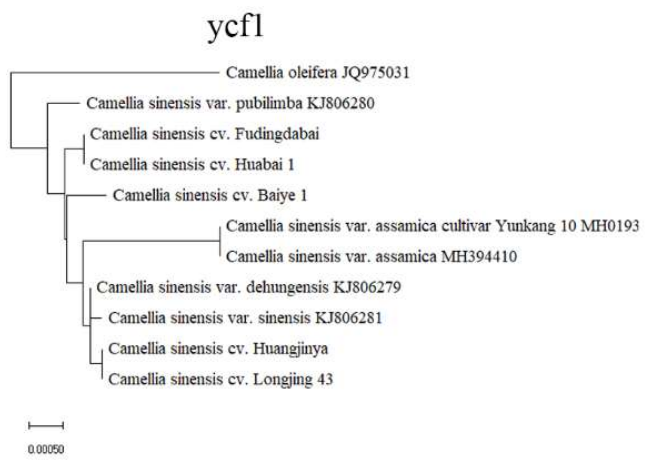

Fig. 4 Phylogenetic tree based on four DNA barcodes in chloroplast genome of tea plants 